Research Article

\title{
Carbothermal Reduction of Iron Ore in Its Concentrate-Agricultural Waste Pellets
}

\author{
Zhulin Liu, ${ }^{1}$ Xuegong Bi $\mathbb{D}^{2},{ }^{2}$ Zeping Gao, ${ }^{1}$ and Wei Liu ${ }^{2}$ \\ ${ }^{1}$ School of Metallurgical and Materials Engineering, Hunan University of Technology, Zhuzhou 412007, Hunan, China \\ ${ }^{2}$ State Key Laboratory of Refractory Materials and Metallurgy, Wuhan University of Science and Technology, Wuhan 430081, \\ Hubei, China \\ Correspondence should be addressed to Xuegong Bi; 1575595611@qq.com
}

Received 22 May 2017; Accepted 24 August 2017; Published 17 January 2018

Academic Editor: Liming Lu

Copyright (C) 2018 Zhulin Liu et al. This is an open access article distributed under the Creative Commons Attribution License, which permits unrestricted use, distribution, and reproduction in any medium, provided the original work is properly cited.

Carbon-containing pellets were prepared with the carbonized product of agricultural wastes and iron concentrate, and an experimental study on the direct reduction was carried out. The experimental results demonstrated that carbon-containing pellets could be rapidly reduced at 1200 to $1300^{\circ} \mathrm{C}$ in 15 minutes, and the proper holding time at high temperature was 15 to 20 min. The degree of reduction gradually increased with temperature rising, and the appropriate temperature of reducing pellets was $1200^{\circ} \mathrm{C}$. The weight loss rate and reduction degree of pellets increased with the rise of carbon proportion, and the relatively reasonable mole ratio of carbon to oxygen was 0.9. A higher content of carbon and an appropriate content of volatile matters in biomass char were beneficial to the reduction of pellets. The carbon-containing pellets could be reduced at high speeds in the air, but there was some reoxidization phenomenon.

\section{Introduction}

In recent years, the research of carbon-containing pellets has attracted great attention of metallurgists. The carboncontaining pellets are composed of iron-containing powders and carbonaceous additives (coke breeze, petro-coke, pulverized coal, peat moss, and charcoal) blended with appropriate binders [1]. They are carbon- and ironcontaining pellets or cold/hot briquettes made through pelletizing in a balling disc or through briquetting in a molding machine after thorough mixing. Carboncontaining pellets were originally used for the production of high-quality sponge iron [2,3], and they could also be fed into the blast furnace. Yokoyama et al. [4] prepared ore/coal briquettes with cement as the binder (blending ratio was 10-11 mass\%) and conducted a 80 day $54 \mathrm{~kg} / \mathrm{t}$ charge test at Oita BF No. 2. A substantial reduction of fuel rate was confirmed by this test. It was attempted to partially substitute biomass char from Japanese cedar for pulverized coal in the preparation of carbon-containing iron ore hot briquettes [5]. The difference of reactivity between wood charcoal, bamboo charcoal, and coal were also investigated [6]. The raw material source of biomass char is wide; however, in China, the forest resource is poor, but the agricultural waste output is great. Charcoal bars made with agricultural crops as raw materials gradually form market for home heating in winter.

It was reported that the carbon content in wheat and corn crops is about $40 \%$ and exceeds $43 \%$ in rice hull. The derived biomass char contains less ash, and the content of impurities such as sulfur and phosphorus are also very low. To apply it for producing carbon-containing pellets will not only contribute to the solution of the puzzle of effectively using agricultural waste in large scale but also improve the quality of iron and steel products.

Effect of several factors such as maximum carbonization temperature of Japanese cypress, reduction temperature, and heating profile on fractional reduction $F(\%)$ after $60 \mathrm{~min}$ was experimentally studied in the laboratory by Hirokazu et al. [7]. Effect of coal content on the apparent density and the cold crushing strength and melt-down temperature of coal composite iron ore hot briquettes was investigated by Hayashi [8]. Kunishi et al. [9] confirmed by the XRD analysis 
of the reduced pellets that the carbon composite iron oxide pellets using the semi-Newcastle blend coal-char at a lower maximum carbonization temperature $(823 \mathrm{~K})$ have the highest reducibility of the iron oxide. Ariyama et al. [10] prepared the composite composed of iron oxide and plastic wastes and confirmed the importance of the composite structure and temperature profile on the effective utilization of pyrolysis gas released from plastics.

Also was studied the impact of residual volatile matters in semicharcoal biomass on the reduction performance of iron ore pellets [11]. Because the reactivity of biomass char outclasses coke, Ueda et al. [12] carried out a research on how biomass char improved the reactivity of carboncontaining pellets. The mole ratio of carbon to oxygen, represented as $\mathrm{C} / \mathrm{O}$ ratio hereinafter, was selected as 1.0. Japanese cedar-derived biomass char, and iron ore powders with no binders were mixed uniformly and pressed in a $10 \mathrm{~mm}$ die at $9.8 \mathrm{MPa}$ to form a tablet of the sample. The temperature inside the test furnace was increased to $1000^{\circ} \mathrm{C}$ at a rate of $0.167^{\circ} \mathrm{C} / \mathrm{s}$, simulating the blast furnace shaft condition. The following main results were obtained: (1) the gasification reaction rate of biomass char is faster than that of coke in a couple of dozen times; (2) the reduction of the composite begins at about $550^{\circ} \mathrm{C}$, and the reactivity of the carbon iron ore composite with biomass char is remarkably faster than that with coke; and (3) the reaction rate of carbon iron ore composite with highlyreactive reducing agent is controlled from both reaction rate of carbon gasification and iron ore reduction.

Takyu et al. [13] tried to understand the reduction mechanism of iron ore and carbon composite by volatile matters in biomass char at low temperature. The iron ore and carbon composite were heated at a constant rate to $1473 \mathrm{~K}$, and the $\mathrm{CO}$ and $\mathrm{CO}_{2}$ concentrations in waste gases were analyzed by an infrared absorption analyzer. It was found that the reduction degree at $1100 \mathrm{~K}$ increased with the amount of volatile matters. By making a comparison between the sample mixed with Biomass char 3 and the sample mixed with coal char, the $\mathrm{CO}$ content was decreased at temperatures below $1000 \mathrm{~K}$ while it was increased at higher temperatures. As for the $\mathrm{CO}_{2}$ content, it was increased when the temperature exceeded $900 \mathrm{~K}$ and reached the maximum at about $950 \mathrm{~K}$, implying the indirect reduction reaction was expedited.

The reducing agents applied in the study of carboncontaining pellets in China and abroad were so far coal and biomass char derived from wood materials. In this paper, the local abundant resource of rice hull and peanut shell in Hunan Province was utilized as raw materials to prepare biomass char, which was used to replace pulverized coal for preparing carbon-containing pellets and to study in laboratory the improvement effect of biomass char on pellets reducibility.

\section{Materials and Methods}

2.1. Experimental Materials. The concentrate for pellet preparation was provided by Xianggang Company, and the chemical composition is listed in Table 1 . The reducing agent
TABLE 1: Chemical composition of the concentrate (mass\%).

\begin{tabular}{llllllllll}
\hline T.Fe & $\mathrm{S}$ & $\mathrm{P}$ & $\mathrm{FeO}$ & $\mathrm{SiO}_{2}$ & $\mathrm{CaO}$ & $\mathrm{Al}_{2} \mathrm{O}_{3}$ & $\mathrm{MgO}$ & $\mathrm{MnO}$ & $\mathrm{H}_{2} \mathrm{O}^{*}$ \\
\hline
\end{tabular}

$\begin{array}{llllllllll}63.55 & 0.05 & 0.01 & 27.02 & 5.47 & 2.86 & 0.93 & 1.00 & 0.33 & 10.20\end{array}$

${ }^{*}$ Free water content.

Table 2: Approximate analysis of biomass chars (mass\%).

\begin{tabular}{lccccc}
\hline Char & $\mathrm{FC}_{\mathrm{d}}$ & $\mathrm{V}_{\mathrm{daf}}$ & $\mathrm{A}_{\mathrm{d}}$ & $\mathrm{S}_{\mathrm{t}, \mathrm{d}}$ & $\mathrm{M}_{\mathrm{ad}}$ \\
\hline$A$ & 61.82 & 32.1 & 3.48 & 0.05 & 2.60 \\
$B$ & 59.79 & 25.88 & 14.2 & 0.05 & 5.13 \\
\hline
\end{tabular}

Note. $\mathrm{A}_{\mathrm{d}}$ : air dry ash content; $\mathrm{V}_{\mathrm{daf}}$ air dry and ash free volatile content; $\mathrm{FC}_{\mathrm{d}}$ : air dry fixed carbon content; $S_{t, d}$ : air dry total sulfur content; $M_{a d}$ internal water content.

TABLE 3: Chemical component of bentonite (mass\%).

\begin{tabular}{cccccccc}
\hline & $\mathrm{Al}_{2} \mathrm{O}_{3}$ & $\mathrm{CaO}$ & $\mathrm{MgO}$ & $\mathrm{SiO}_{2}$ & $\mathrm{~K}_{2} \mathrm{O}$ & $\mathrm{Na}_{2} \mathrm{O}$ & I.L \\
\hline Bentonite & 12.65 & 1.02 & 4.19 & 53.25 & 0.43 & 0.3 & 14.39 \\
\hline
\end{tabular}

was biomass chars prepared from rice husk and peanut shell through crushing, molding, and low temperature carbonization $\left(300-350^{\circ} \mathrm{C}\right)$. In this work, two kinds of biomass chars with different chemical compositions were applied, aiming at studying the influence of char composition on reduction process of carbon-containing pellets. Their chemical compositions are given in Table 2. Bentonite was used as the binder, and its chemical composition is shown in Table 3.

It is seen from Table 1 that $\mathrm{FeO}$ content of the concentrate was $27.02 \%$. The $\mathrm{Fe}_{2} \mathrm{O}_{3}$ content calculated from $\mathrm{FeO} \%$ and the $\mathrm{T} . \mathrm{Fe} \%$ was $60.76 \%$, and the corresponding total oxygen content was $24.23 \%$, stating that this concentrate was a pure magnetite with $\mathrm{T} . \mathrm{Fe} / \mathrm{FeO}=2.35$.

It can be seen from Table 2 that the ash content and sulfur content in biomass char are low. Lower ash content benefits improving the blast furnace performance in terms of the reduction of flux consumption and the smelting of low silicon content pig iron. That the fixed carbon content is low and the volatile content is high is mainly because rather low carbonization temperatures were accepted in the preparation of biomass char, leading to an incomplete pyrolysis. But residual volatile matters will play the role of reduction in the reduction process of pellets because these materials begin to crack and generate $\mathrm{H}_{2}$ and $\mathrm{C}$ as temperature reaches nearly the maximum carbonization temperatures [11]. Also, the temperature range of the pyrolysis is much lower than that of starting reduction of iron oxide; it is therefore essential to design the composite structure and the temperature profile for realizing this temperature difference of the reactions simultaneously in the composite, in order to effectively utilize the pyrolysis gas as a reductant [10].

2.2. Carbon Proportioning. Three molar ratios of carbon to oxygen in pellets were selected for this study, that is, $0.8,0.9$, and 1.0. The corresponding amount of biomass char required for $1 \mathrm{~kg}$ iron ore concentrate, blend ratio of biomass char and carbon content in pellets could be calculated based on the mass balance of carbon and oxygen elements. 


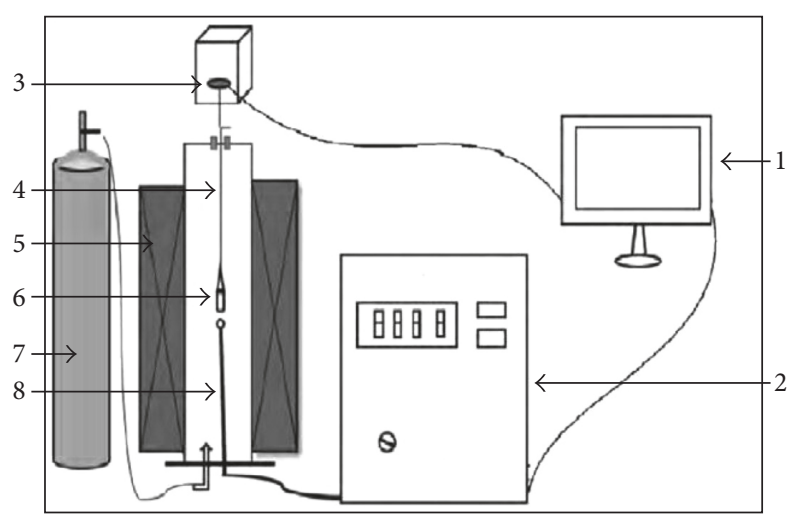

Figure 1: The schematic diagram of experimental apparatus. (1) Computer; (2) temperature controller; (3) electronic balance; (4) Mo wire; (5) $\mathrm{MoSiO}_{2}$ bar; (6) basket and samples; (7) atmosphere controller; (8) thermocouple.

Uniformly mix the concentrate, biomass char and bentonite (additional 6 mass\%) weighed, pelletize the mixture in a balling disc and sift out the $8-12 \mathrm{~mm}$ section. In order to prevent pellets from breaking due to thermal stress in the preheating stage, it is needed to preheat green balls at $105^{\circ} \mathrm{C}$ for $2 \mathrm{~h}$.

2.3. Equipment and Procedure. By applying the thermogravimetry technique (TG), carbon-containing pellets were heated and reduced in a $\mathrm{MoSi}_{2}$ bar electric resistant furnace, and the test apparatus is shown in Figure 1. The temperature of the furnace was measured with a $\mathrm{Pt}-30 \% \mathrm{Rh} / \mathrm{Pt}-6 \% \mathrm{Rh}$ thermocouple, and the sample weight was measured with a $1 \mathrm{~kg}$ electronic balance of $0.001 \mathrm{~g}$ precision. The upper $\mathrm{Fe}-\mathrm{Cr}-\mathrm{Mo}$ wire basket with $30 \mathrm{~mm}$ ID and $100 \mathrm{~mm}$ height was connected with the electronic balance. Ten pellets of 25-30 g total weight with similar diameter were selected for one test, and before use, they were dried at $105^{\circ} \mathrm{C}$ for $2 \mathrm{~h}$. The furnace heated up at $10^{\circ} \mathrm{C} / \mathrm{min}$ as it was below $200^{\circ} \mathrm{C}$ while the heating rate was changed to $15^{\circ} \mathrm{C} / \mathrm{min}$ as it was beyond $200^{\circ} \mathrm{C}$. When the specified experimental temperature was reached, a $\mathrm{N}_{2}$ gas flow was purged at a rate of $3 \mathrm{~L} / \mathrm{min}$. The temperature was kept constant for $5 \mathrm{~min}$, then the basket was quickly put into the furnace together with the sample, and its weight was continuously recorded.

The experiment was conducted isothermally, the reduction temperature was respectively $1000,1100,1200$, and $1300^{\circ} \mathrm{C}$, and reduction time was respectively $5,10,15$, and $20 \mathrm{~min}$. After reduction, the sample was quickly taken out from the furnace and put into a tubular furnace purged with nitrogen for cooling to the room temperature.

2.4. Test Parameter Calculation. For usual iron ores, the degree of reduction can be calculated directly from the weight loss. In the weight loss of carbon-containing pellets, apart from oxygen loss, the carbon loss, the amount of volatile matters separated, and remaining water vaporized are also included. Most researchers made estimation according to the chemically analyzed value of total iron,
TABLE 4: $f_{A-P}$ value of carbon-containing alumina balls under different conditions (\%).

\begin{tabular}{lcc}
\hline Temperature, ${ }^{\circ} \mathrm{C}$ & Molar ratio of carbon to oxygen, - & $f_{A-P}, \%$ \\
\hline \multirow{3}{*}{1000} & 0.8 & 5.76 \\
& 0.9 & 6.17 \\
1100 & 1.0 & 6.74 \\
& 0.8 & 6.30 \\
& 0.9 & 6.64 \\
1200 & 1.0 & 7.35 \\
& 0.8 & 6.32 \\
& 0.9 & 6.65 \\
1300 & 1.0 & 7.49 \\
& 0.8 & 6.33 \\
& 0.9 & 6.66 \\
& 1.0 & 7.49 \\
\hline
\end{tabular}

metallic iron, and $\mathrm{FeO}$ contents in the reduced sample, this method can only obtain the final result of the degree of reduction and could not describe the reduction process. In this paper, the modified weight loss approach was utilized, that is, by taking carbon-containing alumina balls as a reference, to indirectly measure the separation ratio of volatile matters and water and to evaluate the degree of reduction with Equation (1), which originated from a reference and was modified in this work.

$$
R=\frac{4}{7 M_{\mathrm{O}}}\left(f_{\Sigma}-f_{A-P}\right) W \times 100 \%,
$$

where $M_{\mathrm{O}}$ is oxygen amount in iron oxides, $g ; f_{\Sigma}$ is the percentage of total weight loss, $\% ; f_{A-P}$ is the percentage of weight loss of volatile matters and moisture in carboncontaining alumina balls, \%; and $W$ is the weight of carbon-containing pellets, $g$.

It is found in the experiment that release of volatiles is basically terminated at $5 \mathrm{~min}$. The observed values of $f_{A-P}$ at various temperatures and $\mathrm{C} / \mathrm{O}$ ratios are shown in Table 4.

\section{Results and Analysis}

3.1. Effect of C/O Ratio on Reduction of Carbon-Containing Pellets. The plot of reduction degree of carbon-containing pellets with different $\mathrm{C} / \mathrm{O}$ molar ratios at $1200^{\circ} \mathrm{C}$ against time are depicted in Figure 2.

As shown in Figure 2, the $\mathrm{C} / \mathrm{O}$ ratio influences the reduction rate and the degree of reduction at $20 \mathrm{~min}$. As the $\mathrm{C} / \mathrm{O}$ ratio was increased from 0.8 to 0.9 , the reduction was accelerated before $10 \mathrm{~min}$, and it was more obviously accelerated as the $\mathrm{C} / \mathrm{O}$ ratio was further increased to 1.0. The degree of reduction at $20 \mathrm{~min}$ was increased by $5.88 \%$ when the $\mathrm{C} / \mathrm{O}$ ratio was increased from 0.8 to 0.9 , but it almost did not change at all when the $\mathrm{C} / \mathrm{O}$ ratio was further increased to 1.0 , stating that it is reasonable to control the $\mathrm{C} / \mathrm{O}$ ratio at a level of 0.9 .

It was experienced that too high $\mathrm{C} / \mathrm{O}$ ratios will deteriorate the ballability of pelletizing mixture and the strength of product pellets, which would also justify the use of $0.9 \mathrm{C} / \mathrm{O}$ ratio. 


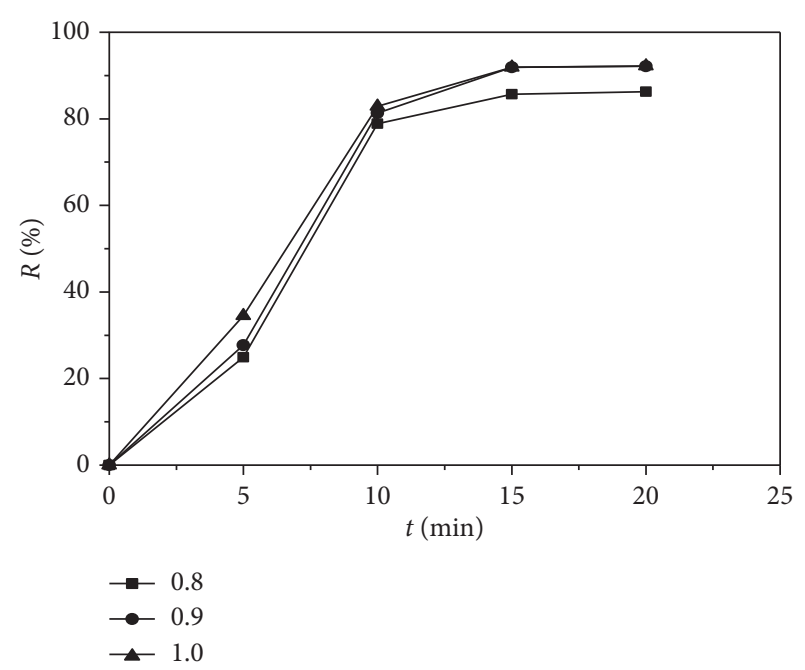

Figure 2: Variation of reduction degree of carbon-containing pellets of different $\mathrm{C} / \mathrm{O}$ ratios with time at $1200^{\circ} \mathrm{C}$.

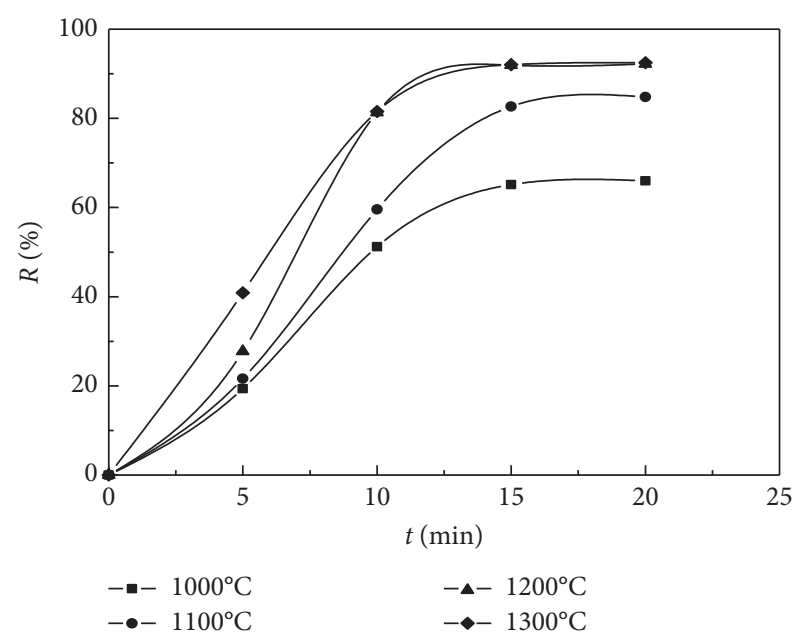

FIGURE 3: Reduction degree of carbon-containing pellets with $\mathrm{C} / \mathrm{O}$ ratio of 0.9 at different temperatures.

\subsection{Effect of Temperature on Reduction of Carbon-Containing} Pellets. The plot of the degree of reduction of carboncontaining pellets $(\mathrm{C} / \mathrm{O}=0.9)$ against time at different temperatures is shown in Figure 3.

It is known from Figure 3 that when temperature is lower than $1200^{\circ} \mathrm{C}$, increasing temperature can substantially promote reduction, and the degree of reduction at $1200^{\circ} \mathrm{C}$ could reach $92.17 \%, 7.37 \%$ higher than at $1100^{\circ} \mathrm{C}$ and $24.83 \%$ higher than at $1000^{\circ} \mathrm{C}$, and that the effect of increasing temperature on reduction improvement was little when it exceeded $1200^{\circ} \mathrm{C}$. It is known that during reduction of carbon-containing iron ore pellets, direct reduction as well as indirect reduction takes place simultaneously. Equilibrium concentration of $\mathrm{CO}$ of $\mathrm{C}$ $+\mathrm{CO}_{2}=2 \mathrm{CO}$ is greater at higher temperatures, and consequently, an increase in temperature contributes to the improvement of indirect reduction of pellets from the view point of reaction kinetics. The direct reduction is an endothermic reaction, stating that an increase in temperature contributes to

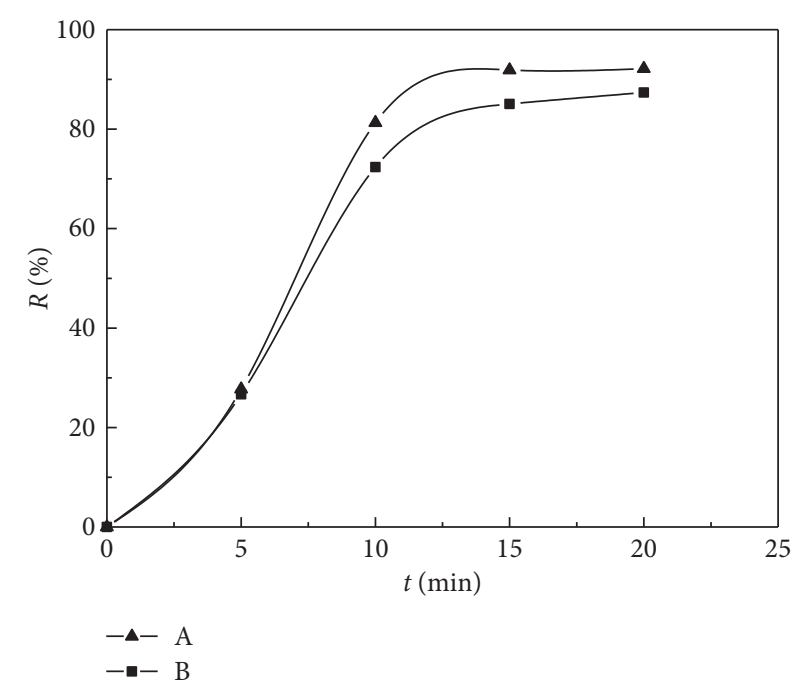

FIgURE 4: Plot of reduction degree of pellets blended with different biomass chars at $1200^{\circ} \mathrm{C}$ against time.

the improvement of direct reduction of pellets from the view point of reaction thermodynamics. Also, an increase in temperature will bring about a more complete escaping and pyrolysis of volatile matters in biomass char. As a result, the degree of reduction was increased with temperature increasing.

When temperature was over $1200^{\circ} \mathrm{C}$, however, the benefit of these aspects reached the maximum, and the effect of further increasing temperature would thus not be substantial.

3.3. Composition of Biomass Char. The carbon-containing pellets blended with char B was reduced isothermally at $1200^{\circ} \mathrm{C}$, and the variation of the degree of reduction with time is depicted in Figure 4. Also in this figure, the reduction experiment results of the carbon-containing pellets blended with char A was shown.

It can be seen from Figure 4 that, in the primary 5 minutes, the reduction behavior of these two kinds of pellets were basically the same, but soon afterwards, the reduction velocity of pellets blended with char B became more and more slowly, the difference with pellets blended with char A enlarged, and at $20 \mathrm{~min}$ the degree of reduction of this couple differed by $4.82 \%$. The ratio of $V_{\mathrm{daf}}$ to $\mathrm{FC}_{\mathrm{d}}$ of char $\mathrm{A}$ is 0.5192 while that of char $\mathrm{B}$ is 0.4328 ; it can thus be understood that at a same $\mathrm{C} / \mathrm{O}$ ratio, the amount of volatile matters in pellets blended with char $\mathrm{B}$ is less than that in pellets blended with char A, meaning that the role played by volatile matters in pellet reduction is less. Furthermore, the escape of volatile matters during reduction will generate vacancies which are favorable for the quick diffusion of CO gas within pellets, contributing to the pellet reduction. The reason from these two aspects brings about that the degree of reduction of pellets blended with char B is not as high as that of pellets blended with char A, and the first reason is the prime.

3.4. Atmospheric Condition. The curve of reduction degree of pellets with $0.9 \mathrm{C} / \mathrm{O}$ ratio under air and $\mathrm{N}_{2}$ atmospheres at $1200^{\circ} \mathrm{C}$ are shown in Figure 5. 


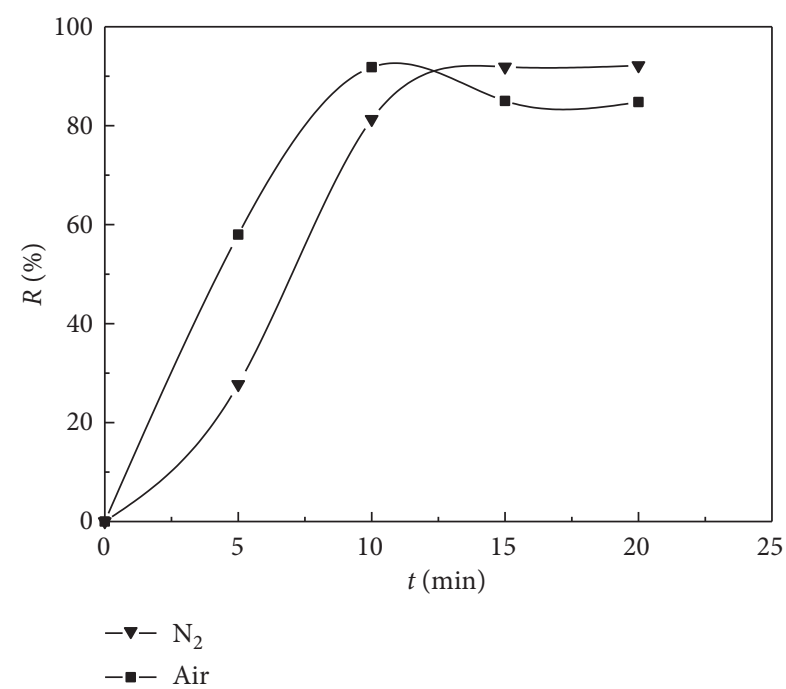

Figure 5: Plot of reduction degree of pellets under different atmospheres at $1200^{\circ} \mathrm{C}$ against time.

It can be seen from Figure 5 that, at $1200^{\circ} \mathrm{C}$, pellets can be reduced at high speeds under the atmosphere of nitrogen and air, and the reduction speed under air atmosphere within the first 10 minutes is even faster. The blend ratio of biomass char in the $0.9 \mathrm{C} / \mathrm{O}$ ratio pellets was $18.60 \%$, and char fines were surrounded by iron ore particles, implying the condition of combustion of char fines is poorer and that the weight loss caused by combustion of carbon would be small. Therefore, it is presumed that the promoted reduction in air would be mainly because $\mathrm{CO}$ gas generated from reduction reacts with oxygen in air and releases heat, supplying the heat consumed by the direct reduction, and that the generated $\mathrm{CO}_{2}$ gas can also impede the reoxidation of iron. Till the final phases of reaction, however, the degree of reduction of pellets gradually decreases, resulted from that along with the combustion of carbon element, the amount of $\mathrm{CO}_{2}$ that plays the role of protection becomes less and less, and part of iron will be reoxidized.

\section{Conclusions}

Carbon-containing pellets were produced with agricultural waste-derived biomass chars, and the influence of factors such as $\mathrm{C} / \mathrm{O}$ ratio, temperature, and char chemical composition on the pellets reduction was experimentally studied, reaching the following conclusions:

(1) The appropriate $\mathrm{C} / \mathrm{O}$ ratio is 0.9 and lower than 1.0 , which is due to the occurrence of indirect reduction and that the volatile content in the biomass char is higher and the $\mathrm{CO}$ and $\mathrm{H}_{2}$ gases generated by the pyrolysis of volatile materials during reduction also take part in the reduction of iron oxides.

(2) As lower than $1200^{\circ} \mathrm{C}$, increasing temperature could substantially promote reduction, the degree of reduction at $1200^{\circ} \mathrm{C}$ could reach $92.17 \%$, when temperature exceeds $1200^{\circ} \mathrm{C}$; however, increasing temperature has little effect on reduction reaction.
(3) The chemical composition of biomass char has an important impact on the reducing properties of carbon-containing pellets, and higher carbon contents and bigger $V_{\mathrm{daf}} / \mathrm{FC}_{\mathrm{d}}$ ratios will promote the reduction reaction.

(4) Carbon-containing pellets could be quickly reduced even in the air atmosphere, in comparison with the reduction tests in the nitrogen atmosphere, and the reduction speed during the first 10 minutes is even higher and the maximum degree of reduction is bigger, but when the carbon blended is essentially completely consumed, the secondary oxidation phenomenon will take place.

\section{Conflicts of Interest}

The authors declare that there are no conflicts of interest regarding the publication of this paper.

\section{Acknowledgments}

The authors thank the Hunan Province (A research project supported by the Hunan Province Science and Technology Program Foundation Grant no. 2012FJ3037).

\section{References}

[1] J. E. Appleby and G. Shaw, "Carbonaceous additives in the pelletizing process," in Proceedings of the 4th International Symposium on Agglomeration, pp. 49-74, Toronto, ON, Canada, June 1985.

[2] W. L. Tennies, J. A. Lepinski, and J. T. Kopfle, "The Midrex Fastmet process a simple economic ironmaking option," MPT, vol. 14, no. 2, pp. 36-42, 1991.

[3] I. Kobayashi, Y. Tanigaki, and A. Uragami, "Direct reduction process using fine ore and coal," in Proceedings of the Asia Steel' 2000, Volume B: Ironmaking, pp. 132-139, Beijing, China, September 2000.

[4] H. Yokoyama, K. Higuchi, T. Ito, and A. Oshio, "Decrease in carbon consumption of a commercial blast furnace by using carbon composite iron ore," ISIJ International, vol. 52, no. 11, pp. 2000-2006, 2012.

[5] S. Hayashi and Y. Iguchi, "Reaction behavior of wood flour added coal composite iron ore hot briquettes at high temperatures," in Proceedings of the Asia Steel International Conference, pp. 372-377, Fukuoka, Japan, May 2006.

[6] M. Kawakami, T. Karato, T. Takenaka, and S. Yokoyama, "Structure analysis of coke, wood charcoal and bamboo charcoal by raman spectroscopy and their reaction rate with $\mathrm{CO}_{2}$," ISIJ International, vol. 45, no. 7, pp. 1027-1034, 2005.

[7] K. Hirokazu, I. Kazuhira, and U. Tateo, "Preparation and reduction of semi-charcoal composite iron oxide pellets," in Proceedings of the 5th International Congress on the Science and Technology of Ironmaking (ICSTI'09), pp. 287-291, Shanghai, China, October 2009.

[8] S. Hayashi, "Reaction behavior of coal composite iron ore hot briquettes in a laboratory scale blast furnace simulator," in Proceedings of the 5th international Congress on the Science and Technology of Ironmaking (ICSTI'09), pp. 423-427, Shanghai, China, October 2009.

[9] H. Kunishi, T. Usui, K. Azuma, and A. Yamashita, "Preparation and reduction behavior of carbon composite iron oxide 
pellets intentionally including residual volatile matter," in Proceedings of the 4th Congress on the Science and Technology of Ironmaking (ICSTI'06), pp. 53-56, Osaka, Japan, November 2006.

[10] T. Ariyama, N. Hayashi, T. Murakami, and E. Kasai, "Reaction behavior of the composite composed of iron oxide and plastic wastes," in Proceedings of the 4th Congress on the Science and Technology of Ironmaking (ICSTI'06), pp. 707-710, Osaka, Japan, November 2006.

[11] H. Konishi, K. Ichikawa, and T. Usui, "Effect of residual volatile matter on reduction of iron oxide in semi-charcoal composite pellets," ISIJ International, vol. 50, no. 3, pp. 386-389, 2010.

[12] S. Ueda, K. Watanabe, K. Yanagiya, R. Inoue, and T. Ariyama, "Improvement of reactivity of carbon iron ore composite with biomass char for blast furnace," ISIJ International, vol. 49, no. 10, pp. 1505-1512, 2009.

[13] Y. Takyu, T. Murakami, and E. Kasai, "Reduction mechanism of iron ore and carbon composite by volatile matters in biomass char at low temperature," CAMP-ISIJ, vol. 27, p. 681, 2014. 


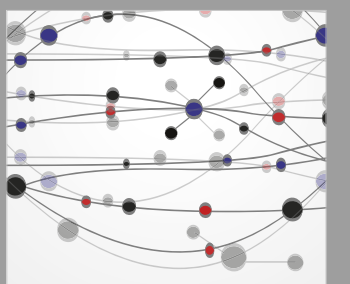

The Scientific World Journal
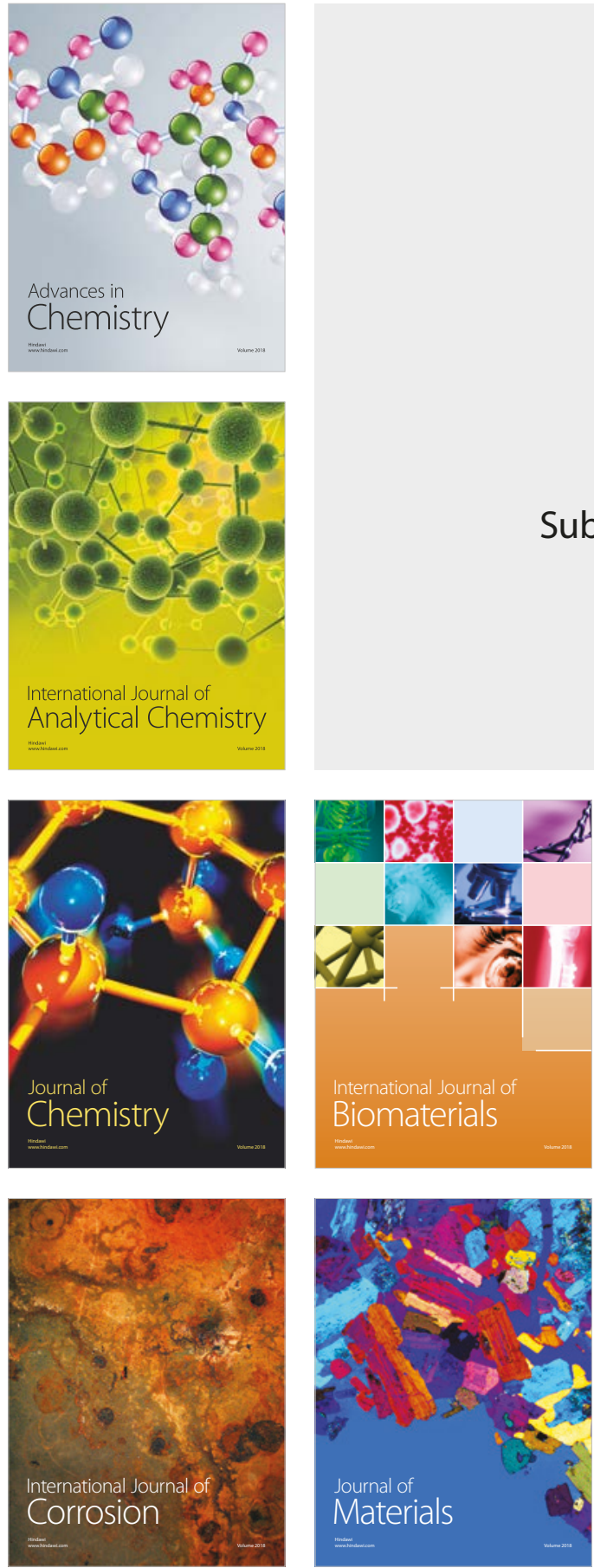

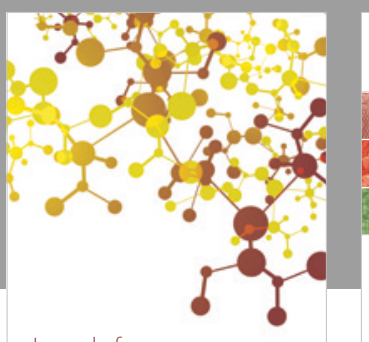

Journal of

Applied Chemistry
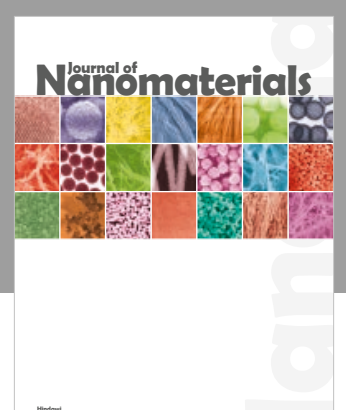

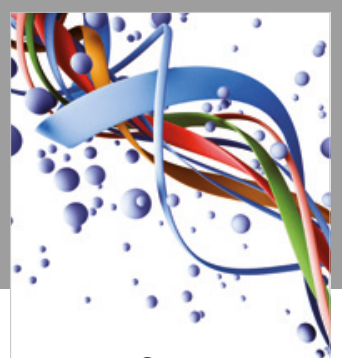

Scientifica

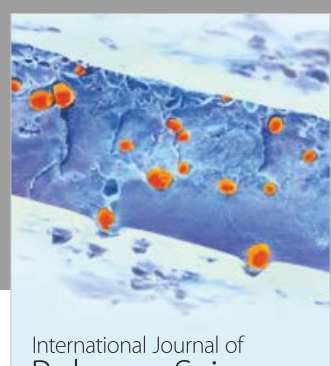

Polymer Science

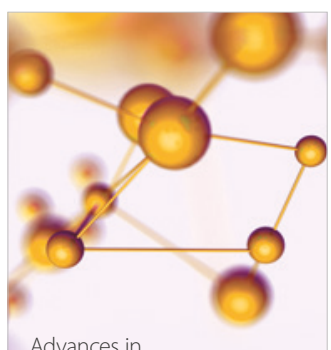

Physical Chemistry
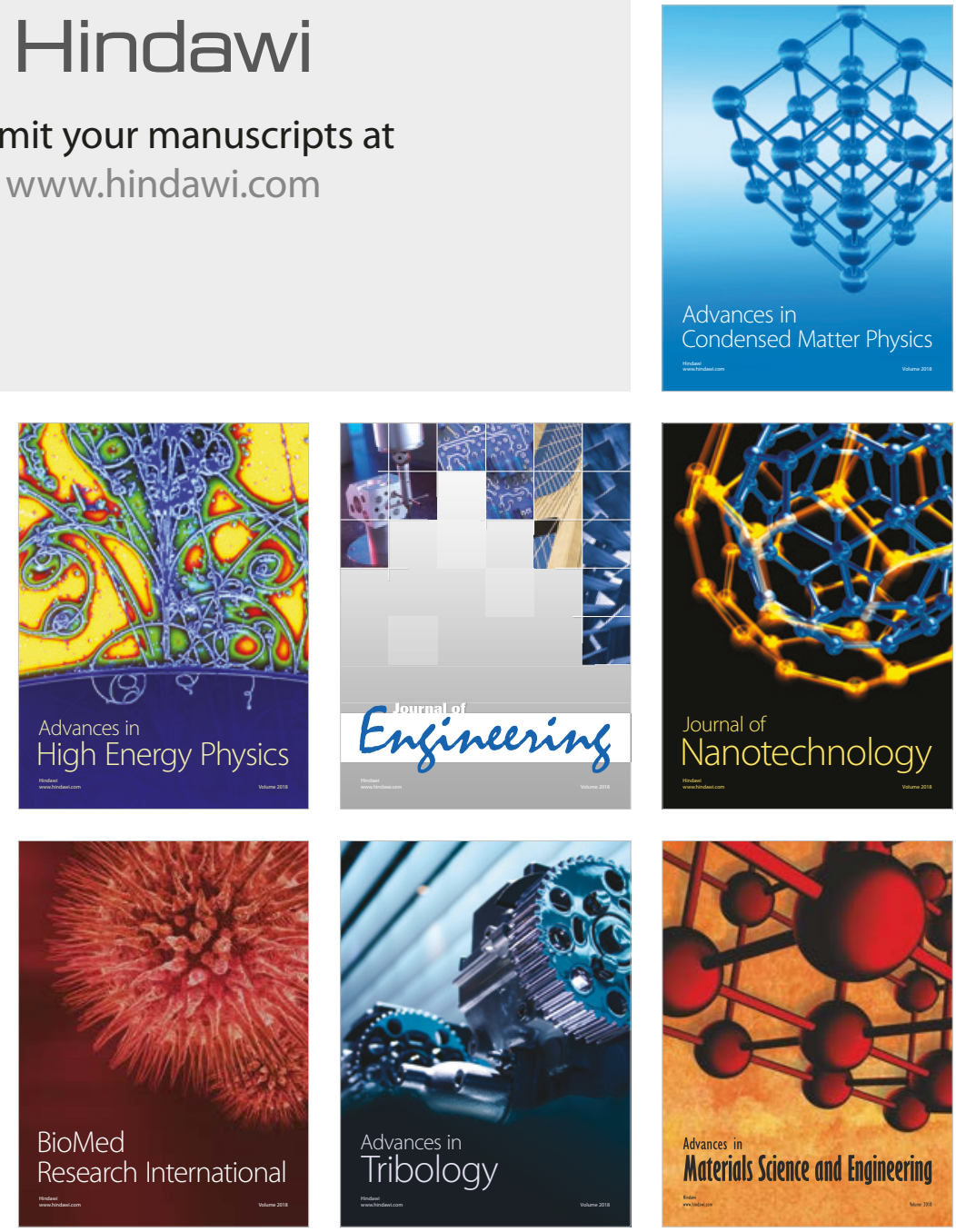